\title{
Afterword: Reflections on Humanities Engagements with the Cultural Politics of Climate Change: Histories, Representations, Practices
}

Julie Doyle

Centre for Spatial, Environmental and Cultural Politics, University of Brighton, Brighton BN2 4GJ, UK;

J.Doyle@brighton.ac.uk

Received: 19 August 2020; Accepted: 1 September 2020; Published: 4 September 2020

check for updates

Understandings of, and responses to, climate change are culturally and historically specific, informed and shaped by a complex set of intersecting social, historical, economic and political systems and representational practices. The Black Lives Matter movement and the Covid-19 global pandemic have brought the historical legacies of structural and systemic racism, and their lived experiences for Black, Indigenous and People of Colour (BIPOC) communities, to the fore. At the same time, feminist and BIPOC scholars and activists call for an intersectional approach to climate and social justice that recognises the ongoing extractivist legacies of capitalism and colonialism, and of racism and white privilege, in the systemic creation and impacts of climate change (Malik 2019; Heglar 2020). Taken alongside the Fridays for Future global youth climate strikes (Figure 1) that have focused attention on the generational and temporal impacts of climate change-that is, upon young people's hopes and aspirations for their (imagined) futures-a critical cultural moment in the politics of climate change is occurring. This moment requires us to work together across disciplines and practices, and ensure a diversity of perspectives, stories and voices are heard.

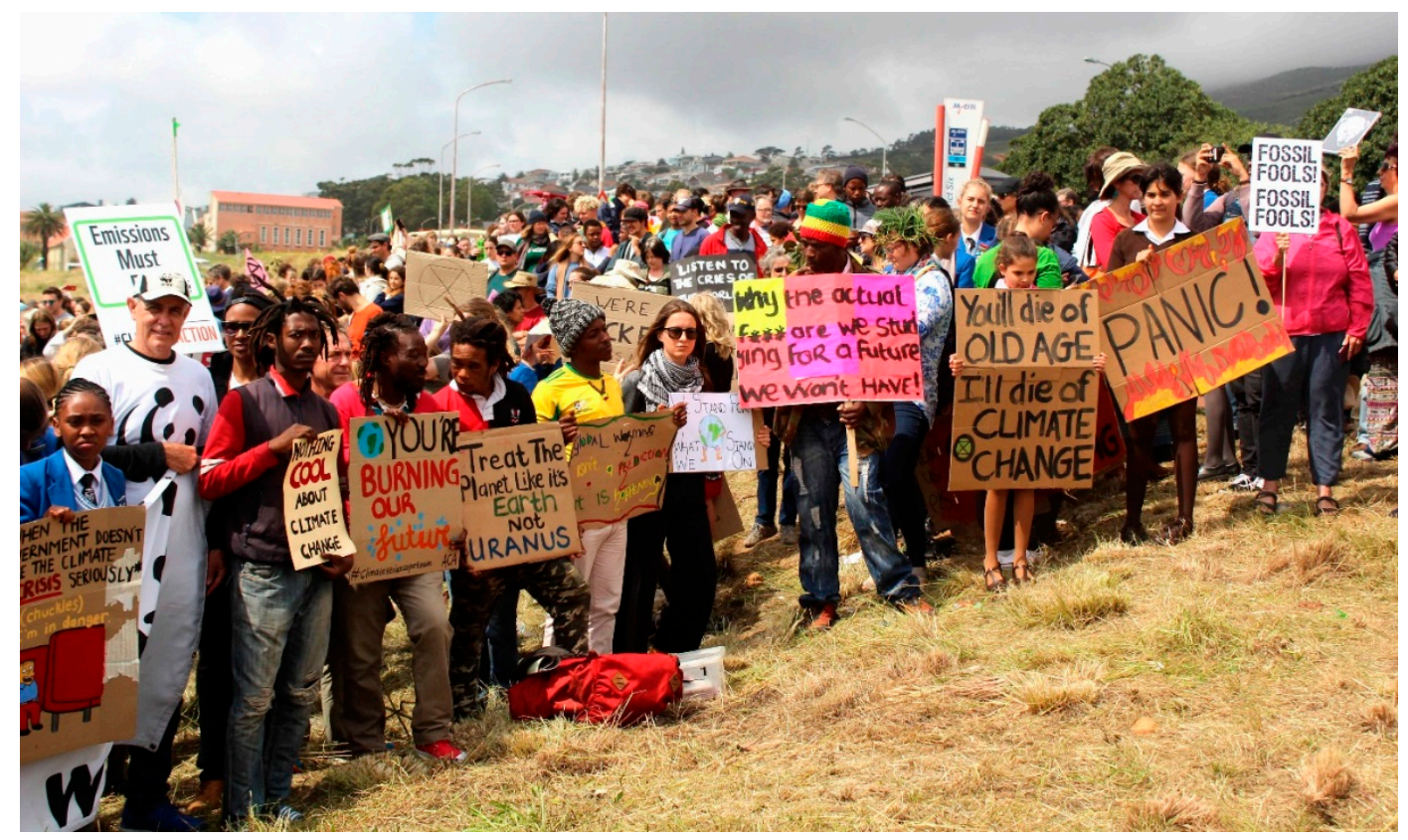

Figure 1. \#ClimateStrike protestors in Cape Town, September 2019. Photo: Masixole Feni/GroundUp.

Humanities approaches to climate change help lend important insights into the ways in which climate change understanding is shaped by intersecting cultural, social and historical forms and 
processes which both enable and constrain particular forms of climate action. As the interdisciplinary papers in this Special Issue demonstrate, exploring the role of cultural values, power relations, and representational and socio-material practices in the formation and (re)interpretation of climate change knowledge and action are key contributions of the humanities. Such perspectives can help to situate climate change within everyday cultural forms and practices as they relate to broader socio-political and economic systems. As such, humanities scholarship is well placed to respond to the calls from climate justice and youth activists to acknowledge and respond to climate change as an intersectional issue of historical, political and cultural importance. Yet, climate change has not always been a focus of humanities scholarship. When I wrote Mediating Climate Change (Doyle 2011) ten years ago, there was significantly less humanities and social science scholarship examining climate change as a cultural and communicative issue. ${ }^{1}$

Written at a specific scholarly moment, and as a white feminist writing from a north-western perspective, Mediating Climate Change also reflected its socio-political time through the cultural and media examples it examined: the communication strategies of an emerging UK climate movement that coalesced around the 2009 Copenhagen Conference but which failed to influence its political outcomes; UK news media coverage of the Copenhagen Conference that grappled with questions of scientific (un)certainty and the urgency of (in)action; emerging NGO campaigns that began to frame meat and dairy consumption as a climate issue; and a growing climate arts movement that offered the potential for more imaginative, embodied and emotional engagements. These visual and textual examples were preceded and informed by an historical analysis and critique of dominant scientific knowledge systems and the representational practices of science, environmentalism and media. These systems and practices, I argued, had come to shape climate communication, understanding and action in problematic ways that separated humans and culture from nature, and rendered climate change as a distant and future threat. In doing so, my intention was to show how historical knowledge systems and representational practices inform contemporary climate understanding and action, with the hope that new forms of climate communication could offer more nuanced understandings of human-environmental relations that link climate change to the cultural politics of the everyday.

Over the last ten years, humanities approaches to the study of climate change have expanded exponentially, helped by the work of journals such as Environmental Communication (since 2007) and Environmental Humanities (since 2012). Scholarship on the cultural and communicative aspects of climate change has contributed to and reflects a significant cultural turn in our understanding of climate (Moser 2016). The work in this Special Issue testifies to the diverse and rich range of critical and creative approaches to the study of climate change that humanities disciplines provide. Encompassing cultural history, literature, anthropology, geography, philosophy, music and art, the papers in this issue draw upon these disciplines to offer interdisciplinary perspectives that contend with key concerns and tensions in understanding climate change as a socio-cultural issue. These perspectives address a number of interwoven and overlapping themes: climate histories, climate representations, climate practices. Addressing climate histories, Nigel Clark demonstrates how a reinterpretation of the socio-material practices of the Holocene can provide critical reflections on contemporary climatic displacements and emplacements. Gillen D'Arcy Wood explores how current climate catastrophe narratives have historical precedence in 19th-century philosophy. Climate representations are examined in Anne Pasek's exploration of different scalar visualisations of climate change and the tensions this produces for facilitating climate engagement and action at the global and everyday level. Ben De Bruyn focuses upon the fictional representations of climate futures that utilise migrant narratives of the present to ground climate change in the everyday and offer more nuanced understandings of climate justice. Anna Boswell demonstrates how a focus upon non-human perspectives can reveal colonial narratives

1 The only other monographs on climate communication and culture published at this time were Hulme (2009) and Boykoff (2011). 
of biodiversity that ignore climate lifeworlds of care and reciprocity. Climate practices are examined in Jeroen Oomen's analysis of the speculative claims of climate geoengineering and their problematic structuring through the conceptual frameworks of Western science. Rosamund Portus and Claire McGinn explore how creative practices of sonic media and participatory arts can offer more embodied climate engagements. Whilst I have situated the papers within these three themes, all of the papers engage with the inter-relations between histories, representations and practices, demonstrating their importance to socio-cultural understandings of climate change.

I began this afterword by situating our understandings of climate change as culturally and historically specific, and drew upon contemporary climate justice politics that highlights the urgency of intersectional understanding and practice. I finish this afterword by taking the opportunity to bring these perspectives together with the work of humanities climate scholarship to foreground the need for scholars, practitioners, educators and activists to work collaboratively together to contribute more ethically and carefully to the critical intersections of the present and future. For example, whilst humanities research can reveal the colonial and capitalist legacies of climate change (see Pasek, this issue), more work needs to be undertaken on exploring how these systemic and representational legacies continue to impact the imaginaries and social practices of everyday climate cultures in raced, gendered and classed ways. In terms of educational contributions, humanities scholars are well placed to collaborate with and contribute to young people's calls for the teaching and learning of climate justice. For example, young people in the UK are campaigning for educational reform through establishment of an English Climate Emergency Education Act that would state 'an expectation on education providers at all levels to deliver teaching and learning on the climate emergency, climate justice (the social injustice issues pertaining from global heating) and ecological crisis' (Teach the Future 2020). Part of this process is addressing climate change as a multidisciplinary issue, beyond the parameters of science and geography. Humanities scholars could provide important collaborative opportunities to work with schools on the reformation of education towards a multidimensional engagement with climate change and climate justice. Creative humanities approaches that utilise participatory methods can, for example, help to engage young people in ways that foreground multidimensional climate learning and agency (Doyle 2020). More work in this emergent area of creative engagements with climate change should be undertaken (Boykoff 2019; see Portus and McGinn, this issue), with a focus upon foregrounding marginalised voices and perspectives.

Finally, a significant challenge for the humanities is how to contribute to the re-imagining and creation of more socially equitable futures that require us to live in/with a climatically changing world (Brown and Imarisha 2015; Haraway 2016). This requires the capacity to understand current societal conditions and to re-think and imagine futures beyond the inequities of the present. A significant strength of humanities scholarship that could help contribute to new social visions has been the focus upon non-human, or more-than-human, species as a means of questioning binary distinctions between nature and culture (Tsing 2015) as products of the racist and gendered politics of colonial extractivism and capitalism. Given the relative lack of media and cultural narratives about equitable climate futures and zero-carbon societies, I suggest foregrounding the importance of these speculations taking place within and through media and popular culture, and actively prioritising marginalised voices and perspectives in this re-imagining (Doyle 2019).

Going forward, humanities research on climate change and climate justice needs to urgently navigate the tensions between researching socio-cultural histories and practices to understand the intersecting power relations and representational practices of present societal conditions, and providing imaginative spaces to explore visions for ethical climate futures. Attending to these needs requires working across disciplines and practices in collaborative and participatory ways, and ensuring research practices have an effect beyond the academy.

Funding: This research received no external funding.

Conflicts of Interest: The author declares no conflict of interest. 


\section{References}

Boykoff, Maxwell T. 2011. Who Speaks for the Climate? Making Sense of Media Reporting on Climate Change. Cambridge: Cambridge University Press.

Boykoff, Maxwell T. 2019. Creative (Climate) Communications: Productive Pathways for Science, Policy and Society. Cambridge: Cambridge University Press.

Brown, Adrienne Maree, and Walidah Imarisha, eds. 2015. Octavia's Brood: Science Fiction Stories from Social Justice Movements. Oakland: AK Press.

Doyle, Julie. 2011. Mediating Climate Change. Abingdon: Ashgate.

Doyle, Julie. 2019. How the Media can Help Young People Create Zero Carbon Societies. The Conversation, September 20. Available online: https://theconversation.com/how-the-media-can-help-young-people-createzero-carbon-societies-123558 (accessed on 10 June 2020).

Doyle, Julie. 2020. Creative Communication Approaches to Youth Climate Engagement: Using Speculative Fiction and Participatory Play to Facilitate Young People's Multidimensional Engagement with Climate Change. International Journal of Communication 14: 2749-72.

Haraway, Donna. 2016. Staying with the Trouble: Making Kin in the Chthulucene. Durham: Duke University Press. Heglar, Mary Annaïse. 2020. We don't have to Halt Climate Action to Fight Racism. HuffPost US, December 6. Available online: https:/www.huffingtonpost.co.uk/entry/climate-crisis-racism-environmenal-justice_n_ 5ee072b9c5b6b9cbc7699c3d?ri18n=true (accessed on 13 June 2020).

Hulme, Mike. 2009. Why We Disagree about Climate Change. Cambridge: Cambridge University Press.

Malik, Laila. 2019. We Need an Anti-Colonial, Intersectional Feminist Climate Justice Movement. AWID, October 3. Available online: https://www.awid.org/news-and-analysis/we-need-anti-colonial-intersectional-feministclimate-justice-movement (accessed on 12 June 2020).

Moser, Susanne. 2016. Reflections on climate change communication research and practice in the second decade of the 21st century: What more is there to say? WIREs Climate Change 7: 345-69. [CrossRef]

Teach the Future. 2020. Available online: https://www.teachthefuture.uk (accessed on 14 June 2020).

Tsing, Anna Lowenhaupt. 2015. The Mushroom at the End of the World: On the Possibility of Life in Capitalist Ruins. Princeton: Princeton University Press.

(C) 2020 by the author. Licensee MDPI, Basel, Switzerland. This article is an open access article distributed under the terms and conditions of the Creative Commons Attribution (CC BY) license (http://creativecommons.org/licenses/by/4.0/). 